\title{
Theoretical Virtues and Theory Adjudication in the Origin of Life Debate*
}

\section{Jeff Wisdom}

\section{Biola University}

When comparing and evaluating rival scientific theories, decisions as to which theory best explains the available data are often made in light of features exemplified by (or at least believed to be exemplified by) one or more of the theories in question. Among these "theoretical virtues" are simplicity, predictive accuracy, internal consistency, fecundity, and the ability to solve external, conceptual problems. Currently, in the debate over life's origin, it appears that the precise role and relative importance of certain theoretical virtues has not yet been established. For example, if the editors of Paleobiology or The Skeptical Inquirer were to receive a manuscript arguing for a special creationist or Lamarckian view of the origin and purpose of the platypus' oddlyshaped bill, it is not likely that they would, at least prima facie, give it much consideration for publication. Similarly, it is unlikely that those at the San Diego based Institute for Creation Research would be convinced by, e.g., Douglas Futuyma's case for human evolution.' Presumably, the representatives of these and other groups come to their respective conclusions not because they are largely ignorant of the available empirical data, but rather because they disagree about what counts as a theoretical virtue in the first place, and because they are at odds regarding how a given virtue ought to factor into one's evaluation of the available data. Lamentably, despite 150 years of conflict over when and how life began, in-depth treatments of theoretical virtues and their role in the debate over life's origin are virtually non-existent. ${ }^{2}$ Nonetheless, when such discussions do appear in print, the virtues most commonly treated are testability, simplicity, and fecundityi.e., fruitfulness for further research. ${ }^{3}$

*I would like to thank Garry DeWeese, Steven C. Meyer, Nathan Hitchcock, and the two anonymous reviewers at $A$ uslegung for their helpful comments and suggestions. 


\section{Testability}

Of the three virtues mentioned above, the one most heavily favored in the current literature, especially among naturalistic evolutionists who tend to see a rigid line of demarcation between science and non-science, with creationism falling to the side of non-science, is that of testability. However, an emphasis on the importance of testability to scientific theories is not limited to naturalistic evolutionists with demarcationist sympathies. Rather, the list of those who emphasize the importance of testability includes even many so-called "young earth" creationists who believe that life on earth began a few thousand years ago as a result of the acts of an all-powerful and loving Creator, and who consider the fossil record to be the result of relatively recent global flood as described in the biblical book of Genesis. While they heartily disagree with evolutionists as to how life began, young earth creationists such as Henry Morris, ${ }^{4}$ and Duane Gish, ${ }^{5}$ concur with, e.g., Niles Eldredge that testability lies at the very heart of scientific enterprise, and that it is the "cardinal virtue" of science itself. ${ }^{6}$ Whether or not they are correct in this assessment, however, remains to be seen.

The fundamental idea behind testability is that a scientific theory must be in principle capable of being falsified. However, this notion can be both elucidated and applied in several different ways. The more philosophically minded person might explain testability in scientific theories by claiming that the proposition(s) essential to a given theory should only make synthetic statements whose truth-values can be known a posteriori. In other words, the primary evidence for a scientific theory must come from entities and phenomena whose existence was discovered (or at least posited) rather than known implicitly or apart from the senses. A more commonly treated aspect of testability is that of predictive accuracy, where a predicted outcome is either directly observable or otherwise empirically verifiable. Here, the observation of a predicted outcome is taken to count in favor of a theory, while failure to make such an observation counts against it. Presumably, the more frequently a scientist can accurately predict future phenomena on the basis of a given theory, the more likely the theory 
is to be true, or at least empirically adequate. Conversely, a theory's reliability and/or explanatory power diminishes with each false or otherwise inaccurate prediction.

Another aspect of testability centers on the fact that certain phenomena naturally occur at regular intervals. Many physical or astronomical theories are testable (at least in part) if they make defeasible claims about naturally recurring phenomena such as red shift or pulsar emissions. Similarly, testability in biological and chemical theories often entails that the conditions under which a state of affairs originally obtained be repeatable under controlled conditions, whether by the scientist who made the initial discovery, or by other scientists in the field. Although this latter aspect of testability may not be the one most germane to the issue of life's origin, there are circumstances in which it could, and, in fact, does come into play. Some naturalistic evolutionists, for example, argue that intelligent design theories are inherently untestable because they do not, or perhaps cannot, refer to phenomena that can be reproduced under controlled conditions. ${ }^{7}$ However, scientists operating under an intelligent design framework could make their theory testable in this way if, for example, they claim to have discovered the genetic limits of viability and adaptability in certain organisms and invite evolutionary biologists to test their results. ${ }^{8}$

However, despite its relevance to science and scientific theories, some philosophers of science have pointed out difficulties in both defining and applying the criterion of testability. For one thing, the fact that one or more scientific theories are testable can in and of itself say very little about whether or not a particular theory should be preferred over any other. Two or more rival theories (e.g., orthodox neo-Darwinism and punctuated equilibrium) may both be testable, but they may also explain the relevant data in very different ways, and an appeal to the testability criterion alone will furnish no help in deciding between the two. A second, more important difficulty in applying the testability criterion is that scientific theories are usually (if not always) tested against a set of background assumptions which include ideas about how to interpret the scientific data and what one would or would not expect to find if a given theory were true. As Moreland notes, when a predicted outcome fails to occur, something has been 
falsified. However, because philosophical and other presuppositions are also involved in the performing and evaluation of scientific experiments, it is often difficult to say precisely what that something is. ${ }^{9}$ Because of this, a theory that is prima facie falsified because of its failure to accurately predict the obtaining of a certain state of affairs could potentially be saved by re-thinking and modifying any of a number of background assumptions. This makes the falsification of certain broad-level scientific theoriesincluding theories of life's origin- an extremely difficult task.

At the risk of being overly brief, the above considerations seem to indicate that in regard to theory adjudication, testability plays two main roles. First, examining a theory with respect to whether or not it can be tested at all helps us separate insightful and/or potentially viable theories from trivial, non-viable ones. Second, considering the means and methods by which a given theory may be tested helps us differentiate between theories that are primarily scientific and those that are primarily philosophical or religious. However, beyond these two roles, (and contrary to current methodology), testability is not the kind of virtue that is among the most applicable in deciding between two or more wellformulated, rival theory-types. In other words, although a specific evolutionary or intelligent design theory of life's origin might be rejected on the grounds that it is not readily testable, testability is not the kind of virtue that could help us decide on the whole between naturalistic evolution and intelligent design. In light of the above considerations, one cannot help but wonder why many philosophers and scientists alike have emphasized this virtue so strongly; often to the neglect of others, such as simplicity.

\section{Simplicity}

Though scientists and philosophers often maintain that simplicity is indicative of (if not essential to) a good scientific theory, it is also fairly common knowledge that defining and applying the concept of simplicity is not at all a simple task. Some, e.g., Kitcher, take simplicity to be akin to the unification of one's methods. That is, a simple theory will successfully solve problems by consistently invoking the same pattern of reasoning. ${ }^{10}$ However, 
the notion of simplicity can also apply to the type and/or number of causal mechanisms posited or required by a theory. Philosophical naturalists and those in search of a "Grand Unified Theory of Everything" are two examples of this. Finally, simplicity could be taken to refer to the number and type of background assumptions upon which a theory is based. That is, one theory could be favored over another if it is based upon well-understood and widely believed assumptions as opposed to ill-defined, tenuous ones.

When evaluating theories of life's origin, a difficulty that arises from having to deal with several different notions of simplicity is that competing theories may be simple in different ways. For example, whereas naturalistic evolutionary theories postulate multiple causal entities necessary for the existence of life in its current form (e.g., mutation, natural selection, differential reproduction, environmental changes), intelligent design theories postulate only one necessary causal entity: God. On the other hand, in examining specific issues (e.g., comparative morphology), intelligent design theories may be based on more numerous and less widely agreed upon assumptions (e.g., that God would replicate the pentadactyl bone structure in animals as widely diverse as whales and humans because it is a good design which works well in several different applications). In a case like this, it is unclear which aspect of the simplicity criterion should take precedence.

It seems, then, that in regard to theory adjudication in general, the criterion of simplicity is perhaps best applied on a case-bycase basis. Furthermore, in the debate over life's origin, it seems that the simplicity criterion is most useful in weeding out specific versions of a theory, and not broad theory-types. Accomplishing this latter task requires the additional work of considering, among other things, the ways in which a theory or theory-type may be more or less fruitful than its rivals. Moreover, we must also seek to determine whether or not there are additional virtues besides testability, simplicity, and fecundity that may be even more applicable in deciding between rival theories of life's origin. But first, we shall examine the virtue of fecundity. 


\section{Fecundity}

It is commonplace to encounter a philosopher or scientist claiming that a good scientific theory will be fruitful, and that the best scientific theory will often (if not always) be the most fruitful one. However, just as simplicity is a complex and often multifaceted issue, so also is the issue of fecundity. One of the oldest and best-known aspects of fecundity is sometimes referred to as the consilience of inductions, or more simply as the virtue of consilience. Here, a fruitful theory is one that is supported by several different lines of evidence; often also accounting for data that is difficult or impossible for other theories to accommodate. Depending on the nature of the theory, this data may originate from either within or outside of the sciences. We might properly call this feature of a theory its "evidentially-based" fruitfulness.

But there are other ways in which a theory may be fruitful. For one thing, a theory may also be pragmatically or technologically fruitful. A theory is fruitful in this sense if it leads to other scientific discoveries or to further technological advances. Medical testing on animals is but one example of this. For some evolutionists, that experimental drugs and medical procedures can be successfully tested on e.g., rats, monkeys, and pigs before prescribing them for human use is an indication of our common descent. Yet another way in which a theory may be considered fruitful is if it is psychologically or methodologically fruitful; that is, if it stimulates new lines of research and greater intellectual rigor among scientists."

Nonetheless, as is the case with testability and simplicity, how one ought to go about deciding which of a given number of theories is the most fruitful is a difficult question. For just as a scientific theory may be simple in ways different from its rivals, a scientific theory may also be fruitful in ways different from its rivals. One theory may enjoy a broader evidential foundation, but lead to little if any further research. A rival theory may have less broadly based evidence, but may lead to great technological advances or spur on more promising theoretical research.

The theory-dependent nature of evidence creates a further difficulty. On one hand, the punctuated equilibrium theory put 
forth by Eldredge and Gould may be more evidentially fruitful than neo-Darwinism in explaining gaps in the fossil record. Here, what is an anomaly for one theory is accounted for by the other. On the other hand, orthodox neo-Darwinism may make better use of known evolutionary mechanisms such as natural selection, mutation, and adaptation than its saltationist counterpart. Similarly, with regard to technological or pragmatic fruitfulness, based on the assumption that a particular biological phenomenon (e.g., information storage and duplication in the cell) is not mere happenstance but is actually an instance of good design, intelligent design theories may lead to greater technological advances, and may even lead to greater discoveries in genetics and microbiology than their naturalistic evolutionist rivals. But when deciding between rival theories, which type of fruitfulness should we favor most heavily? And how should we weigh the value of a theory's simplicity in relation to that of its fecundity or falsifiability, or in relation to the fruitfulness, simplicity, or falsifiability of its rivals? The correct answers, if they exist, are not clear; nor, as we shall see, is it clear (or even likely) that a virtue like fecundity (or testability, or simplicity) ought to factor in more heavily than, say, internal consistency or solving external conceptual problems.

\section{An Evaluation of the Above Virtues}

If nothing else, when one considers even a few of the many background issues involved in the debate over life's origin, it soon becomes clear that deciding between rival theories is not simply a matter of examining the empirical, scientific data. Moreover, in light of the aforementioned considerations, it seems that despite their importance to adjudicating between rival scientific theories in general, due to the level of generality at which theories of life's origin operate and the breadth of data they attempt to explain, the virtues favored by the currently dominant approach do not offer much help when it comes to evaluating such broad-level, rival theories of life's origin as naturalistic evolution and intelligent design. Put differently, the fact that the last 150 or so years of operating under our current methodology has given us no indication that we've come any closer to ending the discussion, along with 
the difficulties inherent in defining and applying the virtues of simplicity, fecundity, and falsifiability, seems to yield the conclusion that, for whatever their merits, problems originating from these considerations lend but modest weight in helping us evaluate the overall plausibility of naturalistic evolution vis-à-vis that of intelligent design. But can any other theoretical virtue(s) offer more help? On one hand, the absence of certain virtues, especially internal, logical consistency, seems to doom a theory from the start. In other words, a theory that is either incoherent or inherently self-contradictory is unbelievable regardless of any empirical evidence. But more importantly, assuming that at least some theories of design and descent are both internally consistent and genuinely scientific, it seems that one of the most promising areas for adjudicating between rival theories of life's origin lies in evaluating their ability to solve external conceptual problems; that is, problems originating outside the sciences that may pose difficulties for a given scientific theory. An example of a potential external conceptual problem for naturalistic evolution lies in the area of epistemology - the study or theory of knowledge. Specifically, we commonly think that part of our rationality as humans lies in the fact that we are able to weigh evidence and come to justified conclusions on the basis of this evidence. However, if the truth of naturalistic evolution entails that all human action is merely the product of chance, heredity, and our environment, then it seems that our decision-making skills are at the mercy of these external factors. If so, then it seems plausible, reliabilist accounts of justification not withstanding, that none of our beliefs are justified, including the belief that naturalistic evolution is true. J.P. Moreland has argued in detail that external conceptual problems ought to play a more prominent role in adjudicating between scientific theories than is currently practiced, ${ }^{12}$ and some evolutionists have noted the inter-relatedness between our scientific and philosophical beliefs. ${ }^{13}$ In a similar vein, the remainder of this essay will examine ways in which certain external, conceptual problems have been brought to bear specifically on theories of life's origin and some consequences that seem to follow for evaluating and justifying beliefs regarding these theories. 
Despite what appears to be an increasing support for scientific pluralism over against a unificationist aim of science, ${ }^{14}$ it seems that when philosophers of science think and write about issues of methodology, they primarily have in mind a methodology fit for certain areas of science (e.g., atomic theory in physics and pathology in biology) whose conclusions generally don't have much relevance for other, non-empirical disciplines. For example, whether or not the Copenhagen school is correct about quantum mechanics doesn't seem to have a direct bearing on whether or not humankind is unique among animals or is, with all life, merely the result of some cosmic accident. Likewise, the truth of oxygen chemistry has implications neither for the morality of embryonic stem cell research, nor for the historical reliability, or lack thereof, of the opening chapters of Genesis. On the other hand, if all life on earth is of common descent and has resulted entirely because of chance, natural selection, and mutation, this could have tremendous and far-reaching implications for other disciplines, especially religion and the humanities. But what about the contrary? Might it not also be the case that considerations from other disciplines can and should play an important part in evaluating scientific theories of life's origin? That the following arguments, among others, exist at all seems to indicate so.

Near the end of his work, The Blind Watchmaker, Richard Dawkins surveys and briefly critiques what he considers to be the major alternatives to neo-Darwinian evolution (e.g., Lamarckism, neutralism, and special creation). He concludes the chapter by putting forth a conceptual argument for Neo-Darwinian evolution to the effect that Darwinism is the only known theory that is in principle capable of explaining such aspects of life as adaptive complexity and the appearance of design. His argument centers on the assumption that we cannot legitimately explain the complexity of certain aspects of the universe by invoking causal mechanisms, (e.g., God), that are themselves complex. For Dawkins, to do so would be to postulate the existence of the very thing we're trying to explain; namely, order and complexity in the universe. In short, Dawkins seems to maintain that the only way 
to explain the order and complexity of life on earth without assuming a priori the existence of complex entities is via some sort of Darwinian evolution. Thus, even if we had no empirical evidence for neo-Darwinism, we still ought to embrace it for purely philosophical reasons. ${ }^{15}$

In addition to the above conceptual argument which could potentially lend considerable extra-scientific support for Darwinism, there are conceptual arguments against Darwinian evolution which should be considered as well. If Hull is correct, then one of the earliest of these arguments originated with John Stuart Mill. Hull contends that one reason Mill ultimately rejected Darwinian evolution is that Mill took statements about species to be laws of nature. If species evolve, it follows that laws of nature are evolving. And if laws of nature can evolve, then we can never know anything about the physical universe, because not even the physical laws themselves are constant. ${ }^{16}$

Taking a somewhat different approach, during the middle of the last century, Richard Taylor argued that if, as naturalistic evolutionists claim, our sensory and rational faculties have arisen apart from the work of one or more supernatural beings, then we are no more justified in believing the deliverances of our reason and our senses any more than we are justified in believing, for example, that a pile of white rocks scattered on a hillside by wind and erosion and resembling the words, "THE BRITISH RAILWAYS WELCOMES YOU TO WALES" gives us reason to think we are in Wales. ${ }^{17}$ A recent, more robust formulation of this type of argument has been put forth by Alvin Plantinga. ${ }^{18}$ Plantinga contends that if our cognitive faculties have originated as Dawkins and others believe, then the objective conditional probability of their being reliable is either low, such that we are unjustified in believing such things as the truth of naturalistic evolution, or it is such that we at least should be agnostic with respect to it. Either way, if Plantinga is right, then evolutionary naturalism is selfdefeating and cannot be rationally believed or accepted.

Perhaps not surprisingly, many remain unconvinced that the above conceptual arguments warrant their conclusions. In fact, a book-length collection of essays devoted solely to Plantinga's evolutionary argument against naturalism has recently appeared 
in print. ${ }^{19}$ For our purposes, however, it is irrelevant whether or not any of these arguments are sound. Rather, the important consideration here is that each of these arguments could potentially establish either neo-Darwinism or intelligent design as the most justified theory of life's origin independently of any empirical evidence whatsoever. As mentioned earlier, if Plantinga's argument (or even Taylor's argument, for that matter) is sound, then the truth of naturalistic evolution would be that none of our beliefs are justified, including the belief that naturalistic evolution is true. If this is the case, then due to the nature of our belief-producing mechanisms themselves, no amount of empirical evidence in favor of naturalistic evolution could bring it about that an individual is warranted in believing naturalistic evolution to be true. Conversely, there seems to be neither any empirical data, nor any consideration based solely thereon, that could have an equally drastic impact on the epistemic status of one's beliefs about life's origin, especially in light of such factors as underdetermination and the previously noted difficulties inherent in defining and applying such virtues as simplicity and testability. But if this is the case, then why think that the current methodology, which gives seemingly unqualified pride of place to empirical data and the theoretical virtues discussed above, provides us with an adequate framework for adjudicating between competing theories of life's origin? Perhaps we should seek instead to embrace a more holistically oriented philosophy of science; one that weighs a theory's merits at least partially on its ability to solve external, philosophical problems such as the ones mentioned above. ${ }^{20}$ Apart from any forthcoming demonstration that, e.g., the available empirical data or a theory's ability to make accurate predictions could have the same "make or break" potential for or against a particular theory of origins, this seems to be a more promising view.

Finally, although a detailed discussion is not feasible here, it should be noted that, in addition to the epistemological considerations mentioned above, problems in other areas of philosophy, including ethics, the philosophy of religion, and the philosophy of mind may also constitute external, conceptual problems for a particular theory of life's origin. Such problems may arise based on either the presuppositions upon which a given 
theory is based, or a theory's philosophical implications. An example of the latter may include the problem of locating consciousness and the first-person perspective in a materialist ontology. Specifically, it seems that a complete, naturalistic evolutionary theory of life's origin should in principle be able to explain, among other things, the origin and nature of human consciousness and the first-person perspective. Currently however, there appears to be nothing even remotely resembling a consensus as to how, exactly, this might be done. If, over time, these phenomena continue to pose a persistent and recalcitrant problem for the materialist ontology on which naturalistic evolution rests, then it seems that short of embracing an eliminativist view of the mental, at some point our failure to come up with an adequate explanation for consciousness and the first-person perspective would provide at least modest grounds for doubting the adequacy of naturalistic evolution as an all-encompassing account of the origin of life and all its putative features. Conversely, if some future naturalistic theory of consciousness were to revolutionize and dominate the philosophy of mind the way that Darwinism currently dominates the sciences, then the explanatory adequacy of naturalistic evolution will be further substantiated. As for an example of an external conceptual problem which might undermine a scientific theory's philosophical foundations, William Lane Craig has recently argued that a robust defense of the kalam cosmological argument provides good reason to believe that a transcendent, personal Creator was the cause of the beginning of the universe. ${ }^{21}$ If Craig's version of the kalam argument is sound, then all naturalistic versions of Darwinian evolution would thus be rendered false. Clearly, such an argument would constitute an intractable external, conceptual problem for naturalistic evolution. Whether Craig is correct on this matter is, of course, hotly debated, but more importantly, despite these and other relevant considerations, discussions of the external conceptual problems that may arise for a given theory of life's origin are nowhere near commonplace within the scientific community, or the intellectual community at large. However, if what I have said here is even approximately correct, then any robust defense of a theory of life's origin ought to take these issues into account, especially in light of the potential 
for certain external conceptual problems to undermine completely one's warrant for holding a particular view.

\section{Conclusion}

Our over-arching concern in this essay has been whether or not the currently dominant approach to theory adjudication in the philosophy of science is adequate for deciding between rival theories of life's origin. For the reasons mentioned above, we have concluded that it is not. Rather, instead of treating the issue of life's origin as a largely scientific question that should be answered primarily (if not solely) on the basis of empirical evidence, we have seen that it involves, among other things, deeply philosophical considerations as well; considerations which are often logically prior to and in some ways more important than an examination of the empirical data. Moreover, since competing theories of human origins have such profound impacts on other areas of thought, and since philosophical and theological concerns often tacitly, if not overtly, factor into the debate, then there is no good reason why we should not be forthright about letting relevant considerations from disciplines outside of science have their say on the matter when appropriate.

Furthermore, in light of what has been said above, it seems that there exist a number of possible scenarios which, given the current intellectual climate, would be epistemically irresponsible if they were to occur, but in fact turn out to be more justified than they initially appear. For one thing, an intelligent design theorist who rejects Dawkins's conceptual argument for Darwinian evolution while accepting one or more of the arguments put forth by Mill, Taylor, and Plantinga against naturalistic evolution seems at least to some degree warranted in holding her view even if there existed seemingly overwhelming empirical support for naturalistic evolution. ${ }^{22}$ Conversely, one who is compelled by Dawkins' conceptual argument for Darwinism could justifiably embrace some forms of Darwinism even if the empirical evidence in its favor somehow turned out to be very weak.

Moreover, it also seems that if there were good philosophical reasons to support an intelligent design view of life's origin (e.g., 
if one or more of the arguments mentioned above were sound), then a scientist or group of scientists who embraced such a view could legitimately carry out their scientific research based on these assumptions. In other words, just as most scientists currently carry out research under the assumption that life in its current form is the result of purely natural processes, there seems in principle no reason why scientists could not also legitimately do research under the assumption that a powerful intelligence is ultimately behind life as we know it. Empirical evidence does, of course, play an important part in confirming or disconfirming specific versions of these differing theories, but only after they have been articulated with a sufficient degree of specificity. However, when it comes to evaluating the overall framework under which scientific research is done, the legitimacy and viability of a given research program should also be based on, among other things, how well its conclusions and implications deal with problems originating from outside the sciences.

If the above contentions are correct, perhaps the most important question we could then ask is, how might this more holistic approach affect our view of life's origin, and how might we come to weigh evidence differently? What might we conclude about the fossil record, or about comparative morphology, or about our current approach to taxonomy? Perhaps if we allow ourselves to be open to these kinds of questions, then data that is commonly thought to be strong evidence in favor of naturalistic evolution will, upon closer inspection, be discovered to be neutral to or even damaging to it. Of course, the evidence for common descent and evolutionary change by purely natural means may remain as strong as advocates of naturalistic evolution say it is, and under the approach being advocated here, it may in fact become even more persuasive. Regardless, it seems clear that the currently popular way of evaluating theories of life's origin is too narrowly construed and does not give proper weight to other areas relevant to the debate. Similarly, it also seems clear that in evaluating such theories there is a legitimate and important place for considerations originating outside the sciences. If we genuinely desire truth (or at least warranted belief) on this issue, then we should be interested in evaluating theories of life's origin not only by their ability to 
accommodate the fossil data in the Burgess shale, but also by whether or not they can adequately account for such things as the contours of our mental life, our ability to communicate via written and spoken language, and the nearly ubiquitous belief in life after death. A more holistic approach to evaluating theories of life's origin may also better enable us to understand and appreciate the ways in which scientific discoveries influence our religious and philosophical beliefs, and vice-versa. Such an approach may even lead to more fruitful scientific research than the current paradigm. More importantly, if we are open and honest with ourselves and with all the available evidence, whether empirical or otherwise, this broader approach may better enable us to arrive at informed, reasonable beliefs about our existence and place in the universe.

\section{Notes}

' See Douglas Futuyma, Science on Trial: The Case for Evolution (New York: Pantheon Books, 1983), 98-113.

2 The best treatment that I have seen thus far on this issue is Kitcher 1982, pp. 30-54.

${ }^{3}$ See, e.g., Kitcher 1982, pp. 30-48; Root-Bernstein 1984, pp. 6568; Gish 1985, p. 12; Morris 1985, pp. 4, 9; Huse 1986, p. 1 and Eldredge 2000, pp. 20-22. For a different approach that is more akin to the position we will be taking here, see J.P. Moreland, "Conceptual Issues, Science, and the Scientific Status of Design and Descent" Perspectives on Science and the Christian Faith 46:2 2-13).

${ }^{4}$ Henry Morris, Scientific Creationism (El Cajon, CA: Master Books, 1985), 4.

s Duane T. Gish, "Creation, Evolution, and the Historical Evidence" in But Is It Science?: The Philosophical Question in the Creation/ Evolution Controversy ed. Michael Ruse (Amherst, New York: Prometheus Books, 1996), 267.

6 Niles Eldredge, The Triumph of Evolution and the Failure of Creationism (San Francisco: HarperCollins, 2000), 78.

' See, e.g., Eldredge 2000, p.91, and Pennock 1999, pp. 194-196.

${ }^{8}$ Some have in fact already done this. See, e.g., Lane Lester and Raymond G. Bolin, The Natural Limits to Biological Change, 2d. ed. (Dallas: Probe Books, 1989).

9 J.P. Moreland, Christianity and the Nature of Science (Grand Rapids: Baker Books, 1989), 33. For a more detailed discussion of the 
importance of auxiliary assumptions and the difficulties they pose for falsifying a theory, see Hempel 1966, pp. 22-25.

${ }^{10}$ Phillip Kitcher, Abusing Science: The Case Against Creationism (Cambridge, MA: The MIT Press, 1982), 47. See also Kitcher 1989, p. 432.

"Some evolutionists have faulted intelligent design-based theories for failing to be fruitful in this way (see, e.g., Root-Bernstein, Robert. "On Defining a Scientific Theory: Creationism Considered" in Science and Creationism ed. Ashley Montagu (New York: Oxford University Press, 1984) 71). For a particularly cogent reply by an intelligent design theorist, see Ratzsch 2001, pp.122-123).

${ }^{12}$ See J.P. Moreland, "Conceptual Issues, Science, and the Scientific Status of Design and Descent" Perspectives on Science and the Christian Faith 45:1 (March, 1994), 2-13.

${ }^{13}$ Hull 1989, p. 65 is particularly relevant. He writes, "Too often the content of scientific theories and our beliefs about the nature of science are treated as if they change in relative independence of each other, when in actual fact their development is closely interlaced. Just as our methodological beliefs influence the content of scientific theories, the content of these theories influences what we take to be proper method." See also John Hodge, "“'Knowing about Evolution: Darwin and His Theory of Natural Selection" in Richard Creath and Jane Maienschein (eds.), Biology and Epistemology, Cambridge Studies in Philosophy and Biology, (Cambridge, MA: Cambridge University Press, 2000), 27-47.

${ }^{14}$ See, e.g., Longino, 2000.

is Dawkins, The Blind Watchmaker, 287-317.

${ }^{16}$ David Hull, "'Why Did Darwin Fail? The Role of John Stuart Mill" in Biology and Epistemology, eds. Richard Creath and Jane Maienschein (Cambridge: Cambridge University Press, 2000), 48-63, 58.

${ }^{17}$ Taylor 1963, pp. 96-102.

${ }^{18}$ Alvin Plantinga, "An Evolutionary Argument Against Naturalism" in Faith in Theory and Practice: Essays on Justifying Religious Belief eds. Elizabeth S. Radcliffe and Carol J. White. (Chicago: Open Court, 1993) 35-66.

${ }^{19}$ James K. Beilby, ed., Naturalism Defeated?: Essays on Plantinga's Evolutionary Angument Against Naturalism (Ithaca, New York: Cornell University Press, 2002).

${ }^{20}$ Although I have thus far emphasized the importance of considering external, conceptual problems in adjudicating the origin of life debate, several other virtues that I have not examined should be considered as well; not the least of which is a theory's aesthetic properties. 
Unfortunately, although several thought-provoking works on beauty and theory adjudication have appeared as of late, e.g., James W. McAllister, Beauty and Revolution in Science (Ithaca, New York: Cornell University Press, 1996), considerations of length and my own lack of proficiency on the subject have prevented me from treating these subjects.

${ }^{21}$ See William Lane Craig, "Design and the Cosmological Argument" in William Dembski, ed., Mere Creation: Science, Faith, and Intelligent Design (Downer's Grove, IL: InterVarsity Press, 1998) 352-359. See also William Lane Craig and Quentin Smith, Theism, Atheism, and Big Bang Cosmology (Oxford: Oxford University Press, 1995).

${ }^{22}$ Of course, if the scientific evidence largely indicates a biohistory of common descent and gradual change due to natural selection and mutation, then the person in question should probably hold to some form of theistic evolution or what Ratzsch calls, "quantum intervention" (Ratzsch 2001, pp. 31-33). Each of these views, though considerably different from the type of intelligent design theory put forth by Johnson, Dembski, Moreland, Meyer, and others, nonetheless have in common the idea that certain aspects of the universe, including the existence of various biological entities and phenomena, are the result of the intentional acts of an intelligent being or beings. For further discussion, see Ratzsch 1996, pp. 186-88.

\section{Works Cited}

Beilby, James K. ed. Naturalism Defeated?: Essays on Plantinga's Evolutionary Argument Against Naturalism. Ithaca, New York: Cornell University Press, 2002.

Craig, William Lane and Quentin Smith. Theism, Atheism, and Big Bang Cosmology. Oxford: Oxford University Press, 1995.

. "Design and the Cosmological Argument." In Mere Creation:

Science, Faith, and Intelligent Design, edited by William Dembski, 352-359. Downer's Grove, IL: InterVarsity Press, 1998.

Dawkins, Richard. The Blind Watchmaker: Why the Evidence of Evolution Reveals a Universe Without Design. New York: W.W. Norton \& Company, 1987.

Eldredge, Niles. The Triumph of Evolution and the Failure of Creationism. San Francisco: HarperCollins, 2000.

Gish, Duane. Evolution: The Challenge of the Fossil Record. El Cajon, CA: Creation-Life Publishers, 1985.

."Creation, Evolution, and the Historical Evidence." In But Is it

Science?: The Philosophical Question in the Creation/Evolution 
Controversy, edited by Michael Ruse, 266-282. Amherst, New York: Prometheus Books, 1996.

Hempel, Carl. Philosophy of Natural Science. Englewood Cliffs, NJ: Prentice Hall, 1966.

Hull, David. The Metaphysics of Evolution. Albany, NY: SUNY Press, 1989.

Huse, Scott M. The Collapse of Evolution. Grand Rapids, MI: Baker Books, 1986.

Kitcher, Phillip. Abusing Science: The Case Against Creationism. Cambridge, MA: The MIT Press, 1982.

Lester, Lane L. and Raymond G. Bohlin. The Natural Limits to Biological

Change. 2d. ed. Dallas: Probe Books, 1989.

Longino, Helen. "Toward an Epistemology for Biological Pluralism." In

Biology and Epistemology, edited by Richard Creath and Jane Maienschein, 261-286. Cambridge, MA: Cambridge University Press, 2000.

Moreland, J.P. Christianity and the Nature of Science. Grand Rapids:

Baker Books, 1989.

"Conceptual Issues, Science, and the Scientific Status of Design

and Descent." Perspectives on Science and the Christian Faith 45:1

March, 1994, 2-13.

Morris, Henry. Scientific Creationism. Carlsbad, CA: Master Books, 1985.

Pennock, Robert T. Tower of Babel: The Evidence against the New

Creationism. Cambridge: MIT Press, 1999.

Plantinga, Alvin. "An Evolutionary Argument Against Naturalism." In

Faith in Theory and Practice: Essays on Justifying Religious Belief, edited by Elizabeth S. Radcliffe and Carol J. White, 35-66. Chicago: Open Court, 1993.

Ratzsch, Del. The Battle of Beginnings: Why Neither Side is Winning the

Creation-Evolution Debate. Downer's Grove, IL: InterVarsity Press, 1996.

. Nature, Design, and Science: The Status of Design in Natural

Science. Albany, NY: State University of New York Press, 2001.

Root-Bernstein, Robert. "On Defining a Scientific Theory: Creationism

Considered." In Science and Creationism, edited by Ashley Montagu,

64-94. New York: Oxford University Press, 1984.

Taylor, Richard. Metaphysics. Englewood Cliffs, NJ: Prentice-Hall, 1963. 